\title{
The Direct Cost of Dialysis in Patients With Chronic Renal Failure in Ouagadougou (Burkina Faso) in 2020
}

\section{Amadou Oury Touré ( $\nabla$ toureamadououry61@gmail.com )}

Cellule de recherche en santé de la reproduction en Guinée (CERREGUI)

\section{Mamadou Dioulde Baldé}

Cellule de recherche en santé de la reproduction en Guinée (CERREGUI)

\section{Aissatou Diallo}

Cellule de recherche en santé de la reproduction en Guinée (CERREGUI)

\section{Sadan Camara}

Cellule de recherche en santé de la reproduction en Guinée (CERREGUI)

\section{Anne Marie Soumah}

Cellule de recherche en santé de la reproduction en Guinée (CERREGUI)

\section{Alpha Oumar Sall}

Cellule de recherche en santé de la reproduction en Guinée (CERREGUI)

\section{Karifa Kourouma}

Centre national de formation et de recherche en santé rurale à Maferinyah Guinée

\section{Bienvenu Salim Camara}

Centre national de formation et de recherche en santé rurale à Maferinyah Guinée

\section{Fadima Yaya Bocoum}

Institute of Health Sciences Research (IRSS) Burkina Faso

\section{Seni Kouanda}

Institut Africain de Santé Publique (IASP) Burkina Faso

\section{Research Article}

Keywords: Direct cost, dialysis, management, chronic renal failure, Burkina Faso

Posted Date: February 8th, 2022

DOI: https://doi.org/10.21203/rs.3.rs-1263341/v1

License: (c) (1) This work is licensed under a Creative Commons Attribution 4.0 International License.

Read Full License 
The direct cost of dialysis in patients with chronic renal failure in

Ouagadougou (Burkina Faso) in 2020.

\section{Authors:}

Amadou Oury Touré ${ }^{1}$, Mamadou Dioulde Baldé ${ }^{1}$, Aissatou Diallo ${ }^{1}$, Sadan Camara ${ }^{1}$, Anne marie Soumah ${ }^{1}$, Alpha Oumar Sall ${ }^{1}$, Karifa Kourouma ${ }^{2}$, Bienvenu Salim Camara ${ }^{2}$, Fadima Yaya Bocoum ${ }^{3,4}$, Seny Kouanda ${ }^{3,4}$

1. Center for Research in Reproductive Health/Cellule de recherche en santé de la reproduction en Guinée (CERREGUI), Conakry, Guinée

2. National Center for Training and Research in Rural Health in Maferinyah Guinea /Centre national de formation et de recherche en santé rurale à Maferinyah Guinée

3. Institute of Health Sciences Research (IRSS) Burkina Faso

4. Institut Africain de Santé Publique (IASP) Burkina Faso

\section{Correspondence author :}

\section{Amadou Oury Touré.}

Email: toureamadououry61@gmail.com

Tel: (00224) 622437976 


\begin{abstract}
Background: Chronic renal failure is a serious pathology requiring renal dialysis. The number of patients under dialysis has increased considerably in the world and particularly in sub-Saharan Africa. Dialysis is a very expensive care. This is the reason why this study on the costs of dialysis management was initiated in Burkina Faso. The study objective is to determine the direct medical and non-medical costs of managing chronic renal failure among patients undergoing dialysis in Ouagadougou in 2020.
\end{abstract}

Methods: An analytical cross-sectional study was conducted. Data were collected in the hemodialysis department of three public university hospitals in Ouagadougou, Burkina Faso. All dialysis patients with chronic renal failure were included in the study. Linear regression was used to investigate the determinants of the direct medical and non-medical cost of hemodialysis.

Results: A total of 290 patients participated in this study, including children, adults, and the elderly with extremes of 12 and 82 years. Almost half of the patients (47.5\%) had no income. The average monthly total direct cost across all patients was 75842 CFA or US\$134.41.The average direct medical cost was 51315 CFA or US\$90.94 and the average direct non-medical cost was 24527 CFA or US\$43.47. Most of the patients (45.2\%) funded their hemodialysis by their own source.

The multivariate analysis showed that the presence of an accompanying person during treatment, residing in a rural area, ambulatory care, use of personal cars, and treatment at the dialysis center of Yalgado Teaching Hospital were associated with higher direct costs.

Conclusion: The average cost of dialysis services borne by the patient and his/her family is very high in Burkina Faso since itis 2.1 times higher than the inter-professional minimum wage in the country (34664 CFA or 61.4 \$US). It appears that the precariousness of the means of subsistence strongly increases with the occurrence of chronic renal failure requiring dialysis. Thus, to alleviate the expenses borne by patients undergoing dialysis, it would be important to extend the state subsidy package to the costs of drugs and to promote health insurance to ensure equitable care for these patients.

Keywords: Direct cost, dialysis, management, chronic renal failure, Burkina Faso. 


\section{Background}

2 Chronic kidney disease is a serious, disabling, and fatal disease. It is nowadays a real public

3 health problem in both developed and emerging countries[1]. Its prevalence and incidence are

4 constantly increasing, mainly due to the aging of the population and the increase of metabolic

5 pathologies that damage the kidneys, including diabetes and hypertension [2]. The number of

6 patients under dialysis has increased dramatically worldwide, including sub Saharan Africa [3].

7 In developed countries, the costs of chronic kidney disease management are generally supported through health insurance mechanisms; these costs vary according to the treatment method[4-6].

In France, the overall cost supported by the health insurance system amounted to 2.1 billion euros in 2005 [7]. While in Switzerland the treatment of chronic kidney disease by hemodialysis costs approximately $€ 80000$ per patient per year [8]. In the Netherlands the annual nonhealthcare cost has been estimated at $€ 8284$ (standard deviation (SD): €14266) for transplant patients and €23,488 (SD: €39434) for dialysis patients[4] . In South Korea, the average annual cost of hemodialysis was $€ 34554$ per patient [9]. In the United States of America, this cost represents nearly $7.1 \%$ of the total Medicare costs[10]

A comparative study in Algeria between the private and public sectors on the evaluation of hospital costs for the management of chronic end-stage renal disease reported that the average cost of care for chronic kidney disease is significantly higher in private facilities than in public facilities, with US\$1313.4 and US\$2800.11 respectively [11]. Direct payment (especially feefor-service) is the commonest mode of payment in Africa and this constitutes a real obstacle to access to care because its leads to a decrease in use of services [3].

In the light of previous studies on the evaluation of the costs of chronic kidney disease management, some evidence have been produced. These pieces of evidence have highlighted the different costs borne by the health insurance, patients, and the public and private structures in 
Africa $[2,4,7,12]$. However, due to the scarcity of studies on this subject in Africa, particularly in the case of Burkina Faso, where renal dialysis is subsidized by government, no data have been reported in the literature on the direct medical and non-medical costs borne by households. However, the lack of knowledge on these costs can lead to inequality and inaccessibility of care for patients.

The objective of this study was to determine the direct cost of managing chronic renal failure among dialysis patients in Ouagadougou in 2020. It is related to direct medical and non-medical costs by focusing on the estimation of the different costs, patients' sources of income, and factors affecting management cost.

\section{Study setting}

Burkina Faso is located in the Sahelian region of West Africa. It has an area of 274,200 km2. The country is administratively divided into 13 regions, 45 provinces, 351 communes, and 8000 villages. It has an agro-pastoral vocation. Agriculture and livestock employ $86 \%$ of the active population and provide 30\% of Gross Domestic Product (GDP) and $80 \%$ of export earnings. The population growth rate is $3.1 \%[13,14]$. According to the Human Poverty Index in 2009, Burkina Faso was ranked 131 st out of 135 countries with an estimated GDP per capita of US\$1124. The majority of its population, $81.2 \%$, lives below the poverty line (US\$2 per day) and $46 \%$ below the national poverty line [15].

The Burkinabe population is predominantly young, with 59\% under the age of 20 [14].

The health system in Burkina Faso has two organizations (administrative and operational). The administrative organization includes the central, intermediate (13 Regional Health Directorates), and peripheral (63 Health Districts) levels; the operational organization includes the first level, which is composed of the Social Promotion Health Centers and the Medical Centers, the second 
level which includes the District hospital, the Regional Hospital Centers and the third level which is the University Hospital Center [16].

\section{Methods}

\section{Study design and period}

An analytical cross-sectional study was conducted. Data collection was carried out from July to August 2020.

\section{Study sites}

This study took place in the three public hemodialysis departments of Ouagadougou, namely those of Yalgado Ouedraogo, Tingandogo, and Bogodogo Teaching Hospitals. These departments were chosen because they are the main referral management centers for renal pathologies all over the country.

\section{Study population}

Our study population was composed of all patients with chronic renal failure undergoing dialysis in the nephrology and hemodialysis departments of the three university hospitals during the study period. All patients with chronic renal failure under dialysis were included in the study, whether they were hospitalized or not in the nephrology or hemodialysis departments the three departments during the study period who had completed at least one (1) month of dialysis sessions and who agreed to be interviewed.

The criteria for non-inclusion in this study were:

-Not giving consent to participate in the study,

-Being a patient under dialysis but has lost his/her invoice for medication, examinations, hospitalization, or consultation, 
-Being a patient under dialysis with a deteriorated general condition, and with no present accompanying person,

-Being a patient with unusable data (medical records, health booklet),

- Being patient with a mental disorder.

\section{Study variables}

These include a dependent variable and independent variables.

Total direct cost is the dependent variable. It is a quantitative variable, expressed in CFA francs. It is the sum of direct medical and non-medical cost. The direct medical cost is the sum of consultation cost, drug costs, laboratory test cost, imaging cost, and hospitalization cost. The direct non-medical cost includes the cost of transportation, food, water, beverages, telephone credits, and fuel. The 17 independent variables included age, gender, education level, marital status, occupation, origin, source of care funding, patient income level, comorbidity, duration of treatment, number of hemodialysis sessions per week, home-hospital distance, means of travel, household size, name of the university hospital, patient accompaniment, residence, and hospitalization.

\section{Data Collection}

Data were collected using a structured questionnaire. The data collection team comprised the principal investigator three medical students. They were trained for two days on: ethical aspects, the definition of direct medical and non-medical cost, filling in the expenditure tables, and postdialysis complications. The questionnaire was then pre-tested for validation. The interviews were done in French and three Burkina Faso local languages (More, Foulfoulde, Dioula). 


\section{Data analysis}

Data were entered using Epidata software, then exported to Stata 15 software for analysis. Descriptive statistics were performed for socio-demographic characteristics. Pearson chi-square and Fisher's exact test were used to compare categorical variables. The Kruskal-Wallis test was used for continuous quantitative variables with skewed distributions to compare group means and categories. We used linear regression to search for determinants of direct medical and nonmedical cost of dialysis has a significance level set at $\mathrm{p}<0.05$. Coefficients were reported with $\mathrm{p}-$ values and $95 \%$ confidence intervals. The modeling was done in several steps. First, we performed a Mackinon's Fe test to check the linear versus a logarithmic form of the variables. This test oriented us towards the log. Thus, we logged the dependent variable (direct medical and non-medical cost) and all quantitative variables that did not have a normal distribution. A univariate top-down regression allowed us to select the variables likely to be included in the model. This allowed us to exclude some variables.

The multi-collinearity test was performed between the independent variables that were significantly associated with the dependent variable in the univariate regression. All the multicollinearity tests were less than 10, suggesting the absence of collinearity between the variables. Subsequently, we performed a multivariate analysis by progressively introducing the independent variables that had been significantly associated with the dependent variable in the univariate analysis and selected after the multicollinearity test. In the same framework of analysis, the multivariate regression model was estimated using the robust Ordinary Least Squares estimator to correct potential heteroscedasticity biases that could affect the normal distribution of residuals and create statistical biases at the same time. Each time we introduced a new variable, we checked the number of observations, the p-value, and the R-squared of the model. The Ramsey reset test was performed to check the specification of the model. Finally, we proceeded to the recovery of the residuals, then the verification of their normalities by the non- 
parametric test of Kolmogorov Smirnov, then the test of Anderson-Darling, and a graphic test for an illustration.

\section{Results}

Table 1 shows that 290 patients participated in the study including children, adolescents, adults, and the elderly. The mean age of the study population was $44.3 \pm 14$ years with extremes of 12 and 82 . The age range of 34 to 44 years was the most frequent. Females represented $40.3 \%$. The most represented socio-professional category was the unemployed (26.2\%), followed by housewives $(18.3 \%)$. Those with no income represented $47.5 \%$. Patients with secondary education represented $42.0 \%$.

\section{Insert table 1}

\section{The direct dialysis cost borne by patients and funding sources}

Overall, the monthly average of direct cost was 75842 CFA (US\$ 134.41) ranging from 2800 CFA (US\$ 5.00) to 1117200 CFA (US\$ 180.06). In the analysis of direct medical cost borne by patients (including consultation, para-clinical examinations, hospitalization, medication, and consumables), the average monthly cost was 51315 CFA (US\$ 90.94) (p-values=0.000), with variation in cost from a hospital to another (Table 2). As for the average direct non-medical cost (transportation, food, fuel, and miscellaneous), it amounted to 24527CFA (US\$ 43.47) with significant variations from a hospital to another $(\mathrm{p}$-values $=0.000)$. The direct non-medical cost represented half of the total direct cost.

As table 2 shows, $45.2 \%$ of patients paid for their dialysis sessions from their own funds. Financial support from parents represented $32.8 \%$ and from children $14.5 \%$. Other important funding sources were friends, colleagues, and associations. Private insurance coverage was only $1.4 \%$ 


\section{Factors associated with the direct cost of managing dialysis patients}

144 Table 3 on univariate linear regression shows that occupation, income, companionship for care, 145 distance, and patient age are statistically associated with dialysis management direct cost. 146 However, after the multivariate analysis, companionship, residence, mode of care, means of 147 travel, and place of care were independently associated with the dialysis management direct cost. Indeed, patients living in rural areas spent 33\% more money on hemodialysis than those living in urban areas (coefficient: 0.338 ; 95\% CI [0.108; 0.567]. As for the mode of medical follow-up, patients who were not hospitalized spent $50 \%$ less money on their hemodialysis than hospitalized patients (coefficient: -0.513 ; IC 95\% [-0.740; -0.286]. Patients using motorcycles to get to the place of care spent $48 \%$ less money than patients who traveled by private cars. Those who used means other than taxi and motorcycle spent more than one time less than those who traveled by personal car. Patients who received care at the Bogodogo Teaching Hospital spent $49 \%$ less than those who received care at the Yalgado Ouedraogo Teaching Hospital.

Insert table 3

\section{Discussion}

Our study on the evaluation of the dialysis management direct cost reveals that the financial burden on patients under dialysis remains high despite the subsidy from the Burkinabe government.

\section{Direct costs}

The monthly average direct cost borne by patients is 75842 CFA (134.41 US\$); this equal to a yearly average cost of 910104 CFA (1613 US\$). Compared to the guaranteed minimum wage 
34664 CFA, this average cost remains very high in the Burkinabe context. Indeed, this direct cost has a non-medical component outside the health structure (transportation, catering, communication costs, etc.) which constitutes half of the cost paid by the patient. In addition, direct medical costs such as examinations, specialist drugs (diuretics) are very high, especially in private drug stores. This cost, therefore, constitutes a financial barrier to access patients' access to care. A study carried out in the city of Kinshasa (Democratic Republic of Congo) in a nonsubsidized context reported an annual average cost of hemodialysis of US $\$ 28,280$, i.e. 22 times higher than the direct cost in Burkina Faso[17]. This low direct cost of hemodialysis found in our context compared to that of the Democratic Republic of Congo could be explained by several factors such as the existence of a subsidy for dialysis in Burkina Faso, the fact that patients do not perform all check-ups and also-they select the drugs to be purchased because of their limited resources.

Other studies have estimated both direct and indirect cost of dialysis. For example, in Iran the estimated total cost of each hemodialysis session was about 74 US\$ and the annual cost per patient was 11549 US\$ [12]. A study reported that in Brazil the average total cost per patientyear is US\$ 28570 for hemodialysis[5]. In Saudi Arabia, the average total cost per hemodialysis session was calculated to be 297 US\$ [1,114 Saudi riyals (SR)], and the average total cost of dialysis per patient per year was 46332 US\$ (173784 SR) [18].

\section{Source of financing}

Our study reports that self-financing $(45.5 \%)$, parental financing, and financial support from children remain the main sources of financing for patients. The low socio-economic level, patients' disability, the lack of payment mechanisms through health insurance or social action could explain this result. In fact, few patients in Burkina Faso have health insurance or social 
action mechanisms. This could be explained by patients' lack of information about health insurance and the rarity of these mechanisms in our context. The absence of these indirect payment mechanisms can lead to inequality of access to care.

\section{Main associated factors}

The place of residence (urban or rural), the type of follow-up, the means of travel, and the place of care (university hospital) were the factors associated with the direct cost of dialysis. Indeed, the presence of a companion during care, residence in a rural area, ambulatory follow-up, use of personal cars, and care in the dialysis center of the Yalgado Teaching Hospital had a significant association with higher direct cost. Other studies in the Democratic Republic of Congo and China found comorbidity and residence environment as factors significantly associated with the cost of dialysis $[6,17]$.

\section{Strengths and limitations of the study}

This is the first study in Burkina Faso to examine the direct cost of dialysis management by patients. It is also one of the few studies that have analyzed the sources of financing for the direct cost of dialysis by patients. As limitations, this study was circumscribed to Ouagadougou public hemodialysis department. Thus, private and the countryside hemodialysis centers were not covered by the research.

\section{Implications for research and practice}

The new knowledge gained from this study contributes to a better understanding of the cost of chronic kidney disease management in Ouagadougou. The results of this study will help to guide advocacy and actions for improving access to chronic kidney disease services in Burkina Faso. A larger study including private and countryside hemodialysis centers will provide more important data for a holistic understanding of the cost for managing chronic kidney disease in 
212 Burkina Faso. Nonetheless, establishing a functional health insurance system is a priority to

213 alleviate health expenses for patients under dialysis in this country.

\section{Conclusion}

215 The average cost of dialysis services borne by patients and their families is very high in

216 Burkina Faso (34664 CFA or 61.4 US\$), representing 2.1 times the guaranteed minimum

217 interprofessional wage. This study revealed that a chronic renal failure requiring dialysis greatly

218 increases the precariousness of patients' livelihoods. Therefore, to alleviate these patients'

219 expenses, it is paramount to extend the state subsidy package to the cost of drugs and promote

220 health insurance for equitable cares. 


\section{Declaration section}

\section{Availability of data and materials}

The data supporting the results of this study are available from [Touré Amadou Oury] but restrictions apply to the availability of these data and are therefore not publicly available, as our research group is working on further analyses using the same data which will then be submitted for publication. However, these data are available upon reasonable request to the corresponding author [Touré Amadou Oury].

Funding: Non Applicable

\section{Author contributions}

Study design: AOT, MDB, FYB. Data collection: AOT. Data analysis: AOT, AD, SC, AMS, AOS, KK, BSC. Initial drafting of the manuscript: AOT, AD, SC, AMS, KK and BSC. Revision of the manuscript: MDB, FYB, SK. The author(s) read and approved the final manuscript

\section{Acknowledgments}

Our thanks go to:

To the Directors of the Teaching Hospital Bogodogo, Tingandogo and Yalgado Ouédraogo, to the heads of the services and to the different teams in the hemodialysis centers, for having authorized this study and for their invaluable help and involvement in the realization of this work.

To Mr. Yann Tapsoba and Mr. Lougmane Ouedraogo for their support in the statistical analysis, their availability and for their immense contribution to the realization of this work.

The authors would like to thank the association of renal failure patients in Burkina Faso for their availability. We also thank all the patients who participated in this study. 


\section{Ethical approval and consent to participate}

We obtained ethical approval $\left(\mathrm{N}^{\circ} 2020-8-165\right)$ from the Ethics Committee for Health Research of Burkina Faso to conduct this study. To respect ethical principles, written informed consent (assent for minors) was obtained from each participant before the interview. The patient could choose to delegate another family member to answer the questions on his or her behalf if the person had more information about the expenses incurred. Confidentiality of the data collected from the participants was ensured during and after the survey.

All methods were applied in accordance with the relevant guidelines and regulations.

\section{Consent for publication}

All participants in this study have given their favorable opinion for the publication of the results.

\section{Competing interest:}

None declared

\section{Author details}

1. Center for Research in Reproductive Health/Cellule de recherche en santé de la reproduction en Guinée (CERREGUI), Conakry, Guinée

2. National Center for Training and Research in Rural Health in Maferinyah Guinea /Centre national de formation et recherche en santé rurale à Maferinyah Guinée

3. Institut de Recherche en Sciences de la Santé (IRSS) Burkina Faso

4. African Institute of Public Health (IASP) Burkina Faso/Institut Africaine de Santé Publique Burkina Faso 


\section{Références}

1. Asserraji M, Maoujoud O, Belarbi M, Oualim Z. Profil épidémiologique de l'insuffisance rénale terminale à l'hôpital Militaire de Rabat, Maroc. The Pan African Medical Journal. $2015 ; 20$.

2. Thuret R, Timsit MO, Kleinclauss F. Insuffisance rénale chronique et transplantation rénale. Progrès en urologie. $2016 ; 26(15): 882-908$.

3. Arogundade FA, Barsoum RS. CKD prevention in Sub-Saharan Africa: a call for governmental, nongovernmental, and community support. American Journal of Kidney Diseases. 2008; 51(3):515-23.

4. de Vries EF, Los J, de Wit GA, Hakkaart-van Roijen L. Patient, family and productivity costs of end-stage renal disease in the Netherlands; exposing non-healthcare related costs. BMC nephrology. 2021; 22(1):1-9.

5. de Abreu MM, Walker DR, Sesso RC, Ferraz MB. A cost evaluation of peritoneal dialysis and hemodialysis in the treatment of end-stage renal disease in Sao Paulo, Brazil. Peritoneal Dialysis International. 2013; 33(3):304-15.

6. Zhang H, Zhang C, Zhu S, Ye H, Zhang D. Direct medical costs of end-stage kidney disease and renal replacement therapy: a cohort study in Guangzhou City, southern China. BMC health services research. 2020; 20(1):1-14.

7. Benain J-P, Faller B, Briat C, Jacquelinet C, Brami M, Aoustin M, et al. Coût de la prise en charge de la dialyse en France. Néphrologie \& thérapeutique. 2007 ; 3(3) :96-106.

8. Vuignier Y, Pruijm M, Jarrayah F, Burnier M. Dialyse et écologie : est-il possible de faire mieux à l'avenir. Rev Med Suisse. 2013 ; 9 :468-72.

9. Kim S-H, Jo M-W, Go D-S, Ryu D-R, Park J. Economic burden of chronic kidney disease in Korea using national sample cohort. Journal of nephrology. 2017; 30(6):787-93.

10. Saran R, Robinson B, Abbott KC, Agodoa LY, Bhave N, Bragg-Gresham J, et al. US renal data system 2017 annual data report: epidemiology of kidney disease in the United States. American Journal of Kidney Diseases. 2018; 71 (3):A7.

11. AZIZI Sabrina, Mr FOUDI Brahim, BOUMRAOU Ounissa. Évaluation des coûts hospitaliers de la prise en charge de l'insuffisance rénale chronique terminale (IRCT) en Algérie:Etude comparative entre deux secteurs l'EPH d' Akbou et clinique privé Rameau d'Olivier dans la wilaya de. 2018.

12. Arefzadeh AR, Mahdavi MM, Lesanpezeshki M, Seyfi S. Cost of hemodialysis in Iran. 2008;

13. Berthé A, Berthé-Sanou L, Konaté B, Hien H, Tou F, Somda S, et al. Les besoins non couverts des personnes âgées en incapacités fonctionnelles à Bobo-Dioulasso (Burkina Faso). Revue d'épidémiologie et de santé publique. 2013 ; 61 (6) :531-7. 
14. Recensement général de la population et de l'habitation (RGPH) de 2006 du Burkina Faso - Résultats Définitifs. Burkina Faso ; 2008 juill.

15. S. Yonkeu, A. H. Maïga, Joseph Wethé, M. Mampouya et G. P. Maga. Conditions socioéconomiques des populations et risques de maladies: Le bassin versant du barrage de Yitenga au Burkina Faso. Revue électronique en sciences de l'environnement. 2003

16. Direction générale des études et des statistiques sectorielles. Annuaire statistique 2017. Burkina Faso ; 2018 avr.

17. Izeidi PP, Nlandu YM, Lepira FB, Makulo J-RR, Engole YM, Mokoli VM, et al. Cost estimate of chronic hemodialysis in Kinshasa, the Democratic Republic of the Congo: A prospective study in two centers. Hemodialysis International. 2020; 24 (1):121-8.

18. Al Saran K, Sabry A. The cost of hemodialysis in a large hemodialysis center. Saudi Journal of Kidney Diseases and Transplantation. 2012 ; 23 (1) :78. 


\section{Supplementary Files}

This is a list of supplementary files associated with this preprint. Click to download.

- Tablesofthearticle.costofdialysisinpatientswithchronicrenalfailureinOuagadougouBurkinaFaso2020.pdf 